\title{
Transcriptome Profiling Analysis of Muscle Tissue Reveals Potential Candidate Genes Affecting Water Holding Capacity in Chinese Simmental Beef Cattle
}

\section{Lili Du}

Institute of Animal Science, Chinese Academy of Agricultural Sciences, Beijing

Tianpeng Chang

Institute of Animal Science, Chinese Academy of Agricultural Sciences, Beijing

Bingxing An

Institute of Animal Science, Chinese Academy of Agricultural Sciences, Beijing

Mang Liang

Institute of Animal Science, Chinese Academy of Agricultural Sciences, Beijing

\section{Xinghai Duan}

College of Animal Science and Technology, Southwest University, Chongqing

\section{Wentao Cai}

Institute of Animal Science, Chinese Academy of Agricultural Sciences, Beijing

\section{Bo Zhu}

Institute of Animal Science, Chinese Academy of Agricultural Sciences, Beijing

\section{Xue Gao}

Institute of Animal Science, Chinese Academy of Agricultural Sciences, Beijing

Yan Chen

Institute of Animal Science, Chinese Academy of Agricultural Sciences, Beijing

\section{Lingyang $X u$}

Institute of Animal Science, Chinese Academy of Agricultural Sciences, Beijing

\section{Lupei Zhang}

Institute of Animal Science, Chinese Academy of Agricultural Sciences, Beijing

Junya Li

Institute of Animal Science, Chinese Academy of Agricultural Sciences, Beijing

Huijiang Gao ( $\sim$ gaohuijiang@caas.cn )

Institute of Animal Science, Chinese Academy of Agricultural Sciences, Beijing

\section{Research Article}

Keywords: Beef cattle, Water holding capacity, RNA sequencing, Differentially expressed genes 
Posted Date: February 3rd, 2021

DOI: https://doi.org/10.21203/rs.3.rs-153911/v1

License: (c) (i) This work is licensed under a Creative Commons Attribution 4.0 International License. Read Full License 


\section{Transcriptome profiling analysis of muscle tissue reveals}

2 potential candidate genes affecting water holding capacity in

\section{Chinese Simmental beef cattle}

4 Lili Du ${ }^{1, \dagger}$, Tianpeng Chang ${ }^{1, \dagger}$, Bingxing An ${ }^{1}$, Mang Liang ${ }^{1}$, Xinghai Duan ${ }^{1,2}$, Wentao Cai ${ }^{1}$, Bo

5 Zhu ${ }^{1}$, Xue Gao ${ }^{1}$, Yan Chen ${ }^{1}$, Lingyang Xu ${ }^{1}$, Lupei Zhang ${ }^{1}$, Junya $\mathrm{Li}^{1}{ }^{1} *$, Huijiang Gao ${ }^{1, *}$

$6{ }^{1}$ Institute of Animal Science, Chinese Academy of Agricultural Sciences, Beijing, 100193, China;

$7 \quad{ }^{2}$ College of Animal Science and Technology, Southwest University, Chongqing, 400715, China;

8 * Correspondence: lijunya@caas.cn; gaohuijiang@caas.cn;

${ }^{\dagger}$ Lili Du and Tianpeng Chang contributed equally to this work.

*Corresponding authors:

Dr. Huijiang Gao

E-mail: gaohuijiang@ caas.cn

Dr. Junya Li

E-mail: lijunya@caas.cn

Emails of the other contributor:

Lili Du: dulili1996@126.com

Tianpeng Chang: changtianpeng@126.com

Bingxing An: ABX2HF@ 126.com

Mang Liang: liangmang87@163.com

Xinghai Duan: xhduan0411@163.com

Wentao Cai: caiwentao@caas.cn

Bo Zhu: zhubo525@126.com

Xue Gao: gaoxue76@126.com

Yan Chen: chenyan0204@163.com

Lingyang Xu: xulingyang@caas.cn

Lupei Zhang: zhanglupei@caas.cn 


\section{Abstract}

Water holding capacity (WHC) is an important sensory attribute that greatly influences meat quality. However, the molecular mechanism that regulates the beef WHC remains to be elucidated. In this study, the longissimus dorsi (LD) muscles of 49 Chinese Simmental beef cattle were subjected to RNA sequencing (RNA-seq), among which eight individuals with the highest WHC (H-WHC) and the lowest WHC (L-WHC) were selected for transcriptome analysis. A total of 1256 genes were identified as differentially expressed genes (DEGs) between two groups, of which 948 genes were up-regulated and 308 genes were down-regulated. Gene Ontology (GO) and Kyoto Encyclopedia of Genes and Genomes (KEGG) pathway enrichment revealed that DEGs were significantly enriched in 24 GO terms and 78 pathways. Additionally, based on protein-protein interaction (PPI) network, animal QTL database (QTLdb), and relevant literature, the study not only confirmed seven genes (HSPA12A, HSPA13, PPAR, MYH10, MYL2, MYPN, and TPII) influenced WHC in accordance with previous studies, but also identified six genes (ITGAV, FGF2, THBSI, DCN, COLAA1, and TGFBRI) as the most promising novel candidate genes affecting the WHC. These findings could offer important insight for exploring the molecular mechanism underlying the WHC trait and facilitate the improvement of beef quality.

Keywords: Beef cattle; Water holding capacity; RNA sequencing; Differentially expressed genes

(1)

(1)

1

2

3

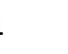

5

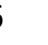

8

9

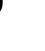




\section{Introduction}

Meat quality has been measured by multiple indicators such as WHC, drip loss, intramuscular fat (IMF), shear force (SF), and meat color that are economically important traits with low to medium genetic heritability $\left(h^{2}\right)^{1-5}$, among which WHC is an important meat sensory attribute that contributes to improving the quality and yield of meat. Previous researches about ruminants demonstrated that extremely low WHC due to myoprotein degradation was the main cause of pale, soft, and exudative (PSE) meat, while high WHC caused by high $\mathrm{pH}$ could explain the production of dark, firm, and dry (DFD) meat ${ }^{6}$.

WHC is defined as a measurable characteristic related to the ability to retain inherent water in meat under the influence of intrinsic (i.e., genotype) and extrinsic (i.e., pre-slaughter and post-slaughter treatment methods) factors ${ }^{7}$. Drip loss is the most important method to assess WHC that defined as the fresh meat loss rate under gravity at $0-4{ }^{\circ} \mathrm{C}$ for $24 \mathrm{~h}^{8}$. Several studies showed that the genotype played roles in the bovine WHC trait. In the work of Martínez et al., WHC was proven to exist in differences between diversified genotypes $(p<0.01)$, which is greater in normal $(+/+)$ bulls, intermediate in heterozygous $(\mathrm{mh} /+)$ bulls, and least in homozygous $(\mathrm{mh} / \mathrm{mh})$ bulls ${ }^{9}$, which was consistent with the conclusions drawn by Uytterhaegen et al. in the Belgian Blue breed ${ }^{10}$ and by Oliván et al. in the Asturiana de los Valles breed ${ }^{11}$. Age, sex, stress, and stunning during the pre-slaughter period, as well as chilling and aging in the post-slaughter period, and meat processing methods (i.e., cooking and cooling temperature, cooking and cooling rates, etc.) all influenced the WHC ${ }^{7,12}$. Sazili et al. suggested that in comparison with cattle stunned by low power non-penetrating mechanical stunning (LPNP) method, those stunned by high power non-penetrating mechanical stunning (HPNP) method showed a lower WHC and lightness $\left(\mathrm{L}^{*}\right)^{13}$. Brad Kim et al. concluded that cryogenic freezing could lead to a significant increase in WHC and decrease SF values significantly ${ }^{14}$. WHC could directly affect other meat quality parameters, which was positively related to IMF content while negatively regulated drip loss and cooking loss ${ }^{15-17}$. PH was also a major element affecting the $\mathrm{WHC}^{18}$. Farouk et al. found WHC was higher in Bovine M. semimembranosus with inherently higher $\mathrm{pH}$ compared to lower $\mathrm{pH}^{19}$. Conversely, Wen et al. revealed WHC had significant and negative genetic correlations with $\mathrm{pH}^{16}$. The reason for the opposite conclusions of the above studies on the correlation between WHC and $\mathrm{pH}$ was that WHC was measured at different periods after animal slaughter.

In the researches of WHC, several candidate genes relevant to the trait have been identified in domestic animals. Serpin family G member 1 (SERPING1) ${ }^{20}$, cysteine and glycine-rich protein 3 $(C S R P 3){ }^{21}$, phosphorylase kinase gamma subunit $(P H K G){ }^{22}$, ryanodine receptor $1(R Y R I)^{17}$,

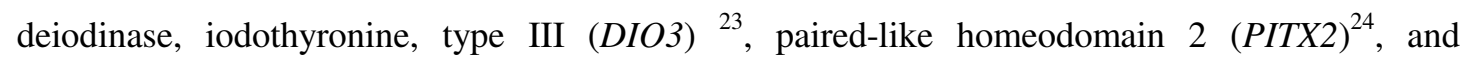
complement component 4 binding protein, alpha (C4BPA) ${ }^{20}$ located on SSC 2, SSC 2, SSC 3, SSC 6, SSC 7, SSC 8 and SSC 9, respectively, have been proven to be related to the WHC trait of pork. Myostatin $(M S T N)^{9}$, peroxisome proliferator-activated receptor gamma $(P P A R \gamma)^{25}$, and 
myopalladin $(M Y P N)^{26}$ mapped to BTA 2, BTA 22, and BTA 28, respectively, were identified as critical candidate genes responsible for beef WHC relying on previous studies. Besides, calpastatin $(C A S T)$, the specific inhibitor of the calpain family of endogenous proteases, is not only related to WHC but also correlated with tenderness in beef ${ }^{27,28}$.

With the development of next-generation sequencing technology (NGS), high-throughput RNA sequencing (RNA-seq) has gradually become an indispensable tool for constructing transcriptome profiling and understanding the molecular mechanisms of biological processes ${ }^{29}$. However, few relevant studies on WHC were performed in beef and the knowledge of molecular mechanisms underlying the trait remained elusive. The WHC trait was moderate heritability $(0.33 \pm 0.10)$, showing, thereby it was not easy to improve WHC by conventional breeding methods ${ }^{5}$. The purpose of this study is to use the RNA-Seq technique, functional enrichment tools, PPI network, and QTLdb to identify the crucial candidate genes, significant GO terms and pathways affecting the regulation of WHC, aiming to improve the WHC trait, enhance beef quality and flourish the beef industry by using molecular breeding technologies.

\section{Results}

\section{Phenotypic information of Chinese Simmental beef cattle}

A total of 49 individuals were ranked by WHC in descending order, divided into the H-WHC group $(0.53 \% \leq \mathrm{WHC} \leq 0.70 \% ; \mathrm{n}=4)$ and the $\mathrm{L}-\mathrm{WHC}$ group $(0.30 \% \leq \mathrm{WHC} \leq 0.44 \% ; \mathrm{n}=4)$. The average of WHC in high and low groups was $0.62 \%$ and $0.39 \%$, respectively $(\mathrm{p}<0.05)$. Their detailed information on carcass and meat quality traits between the two groups was presented in Table 1 and Supplementary Table S1. In comparison with the L-WHC group, the H-WHC group showed lower $35 \mathrm{~kg}$ Water loss $(\%)(\mathrm{p}<0.05)$ of LD muscle, demonstrating WHC had a significantly negative correlation with water loss, which was consistent with previous studies ${ }^{5,15,16}$. Additionally, the animals grouped by WHC were similar in age and there was no significant difference in weight for pre-slaughter between them $(p>0.05)$, which could decrease the error of WHC measurement. Consequently, the samples could be used for RNA-seq to detect genes associated with the WHC.

\section{Summary of RNA sequencing data and alignment of bovine LD muscle}

The transcriptome sequencing of LD muscle tissue was conducted by RNA-seq approach for paired-end strategy (read length 150 bp) on an Illumina NovaSeq 6000 platform. As a result, a total of $186,968,565$ raw reads, ranging from $19,721,321$ to $29,214,147$ for each sample were generated. After quality control (i.e., filtering low-quality reads), a total of 177,433,007 (an average of $22,179,126$ ) clean reads were obtained for the 8 samples, and the quality values of Q20 and Q30 were above $98.09 \%$ and $94.37 \%$, respectively. These results indicated that the RNA sequencing quality of the samples was high and could be used for sequence alignment. Through 
alignment, an average of $97.03 \%$ of clean reads was mapped to the Bos taurus reference genome, of which $90.48-92.13 \%$ and $2.71-3.75 \%$ of clean reads per sample were uniquely mappable and multiple mappable, respectively. The information on sequencing results was listed in Table 2 and Supplementary Table S2. The alignment of clean reads confirmed the reliability of the RNA-seq, which could be used for subsequent analysis.

\section{Transcriptome profiling of DEGs with high and low WHC}

In order to investigate the transcriptome expression profiling of the LD muscle with different WHC, the gene expression levels between H-WHC and L-WHC groups were compared by using the DESeq2. Figure 1A showed two groups of individuals grouped by extreme WHC values were obviously clustered through Principal Component Analysis (PCA), which demonstrated the selection of the experimental population is reasonable. According to empirical studies, genes with a fold discovery rate (FDR) adjusted p-value less than 0.05 (padj $<0.05$ ) and fold change $\geq 2$ or fold change $\leq 0.5\left(\log _{2} \mathrm{FC} \geq 1\right.$ or $\left.\log _{2} \mathrm{FC} \leq-1\right)$ were identified as DEGs. As shown in Figure 1B, compared with the L-WHC group, a total of 1256 genes were identified as DEGs in the H-WHC group, of which 948 genes were up-regulated $\left(\log _{2} \mathrm{FC} \geq 1\right.$ and padj $<0.05$ ) and 308 genes were down-regulated $\left(\log _{2} \mathrm{FC} \leq-1\right.$ and padj $\left.<0.05\right)$. The results of all DEGs were displayed in Supplementary Table S3. Furthermore, Figure 1C indicated the hierarchical clustering of heatmap depended on all DEGs was consistent with PCA analysis. Red and blue indicated the high-level and low-level gene expression in the H-WHC group versus the L-WHC group, respectively, which showed the gene expression patterns were consistent within groups and different between groups.

\section{GO and KEGG pathway enrichment analyses}

GO and KEGG enrichment analyses were performed to understand the function of the DEGs between the H-WHC and L-WHC groups. Figure 2A showed the significantly enriched GO terms ( $\mathrm{p}$-value $<0.01$ and q-value $<0.05$ ). A total of 24 significant GO terms were enriched, among which 15 terms were involved in biological process (BP) category (cell adhesion, biological adhesion, and muscle fiber development, etc.), eight terms were enriched in cellular component (CC) category (cell junction, extracellular matrix, and cell surface, etc.), and only one term participated in molecular function (MF) category (glycosaminoglycan binding). As shown in Table 3, among these GO terms, a large number of DEGs were enriched in cell adhesion, biological adhesion, cell surface, and extracellular matrix, implying that these biological processes might play crucial roles in the WHC trait. Figure 2B and Table 3 displayed the significantly enriched pathways of DEGs were mainly associated with environmental information processing, including the mitogen-activated protein kinase (MAPK) signaling pathway (bta04010), Calcium signaling pathway (bta04020), etc. Ten pathways were involved in human diseases and organismal systems, respectively, and two pathways were proven to be closely related to cellular processes, such as focal adhesion (bta04510) and regulation of actin cytoskeleton (bta04810). The detailed 
information about significantly enriched GO and KEGG pathways was shown in Supplementary Table S4 and Supplementary Table S5. Additionally, all pathways enrichment of the DEGs were listed in Supplementary Table S6, which included the regulation of signaling molecules and interaction such as ECM-receptor interaction (bta04512) and cell adhesion molecules (bta04514). Most of the KEGG pathways were closely associated with signal transduction, cell growth, cell proliferation, cell division, cell differentiation, and muscle development.

Figure 3 showed the network diagram where the DEGs were significantly enriched in some GO terms and pathways. The DEGs associated with more than three GO terms or pathways could be recognized as potential candidate genes regulating WHC. Consequently, ITGAV, FGF2, THBS1, $D C N, C O L A A 1$, and TGFBRI were identified as novel potential candidate genes regulating WHC following the transcriptome analysis. Table 4 showed the information of these six genes.

\section{Screening DEGs based on QTLdb and previous reports}

To further search for vital candidate genes that affect WHC, we analyzed the DEGs in the cattle QTL database (https://www.animalgenome.org/cgi-bin/QTLdb/BT/index, Release 42, Aug 27, 2020). QTLs for drip loss or WHC have been found on BTA 1, 2, 4, 7, 11, 14, 19, 22, 28, and 29. However, genes influencing the WHC or drip loss identified in these QTLs remain still very limited. As listed in Supplementary Table S7, only a total of 15 QTLs in the cattle QTL database were reported to be associated with WHC and drip loss, which indicated a lack of researches on cattle WHC. Besides, we also confirmed several genes affecting the WHC that had been proven by previous studies, which was shown in Table 5. Consistent with previous studies, HSPA12A, HSPA13, PPAR , MYH10, MYL2, MYPN, and TPI1 were also identified as DEGs (padj < 0.05 and $\left.\left|\log _{2} \mathrm{FC}\right| \geq 1\right)$ in this study and these genes played an important role in the WHC trait. When broadening the threshold at only padj <0.05, MYPN (padj $=3.48 \mathrm{E}-02, \log _{2} \mathrm{FC}=0.59$ ) was differently expressed in the two groups. The information on these genes could be searched in Supplementary Table S3 and Supplementary Table S8.

\section{PPI analysis of candidate genes}

To visualize the interaction between node proteins encoded by potential candidate genes, we used Search Tool for the Retrieval of Interacting Genes (STRING) for PPI network analysis, which was shown in Figure 4. Genes that had been confirmed by previous studies to be related to WHC were marked in red (HSPA12A, HSPA13, PPAR, MYH10, MYL2, MYPN, and TPI1), and the potential candidate genes speculated in this experiment that influenced WHC were marked in blue (ITGAV, FGF2, THBS1, DCN, COLAA1, and TGFBR1). The detailed information of all candidate genes was listed in Supplementary Table S8 and the involvement of these genes in GO terms and KEGG pathways were presented in Supplementary Table S9. 
223 WHC is an important meat sensory attribute associated with pH, meat color, and IMF ${ }^{15-17}$. 224 However, the molecular mechanisms underlying the development of WHC are still limited. In the study, we selected eight Chinese Simmental beef bulls with extremely high and low WHC to analyze their LD muscle expression profiles by using RNA-seq technology. A total of 1256 DEGs were detected, of which 948 were up-regulated and 308 were down-regulated. To identify potential candidate genes and further understand the function of critical DEGs related to WHC, GO enrichment, KEGG pathway analysis, and comparison with the QTLs influencing WHC in QTLdb and relevant literature were carried out. A total of 13 critical DEGs significantly enriched in more than three GO terms or pathways were recognized as potential candidate genes affecting WHC and the PPI network showed the relationship between key node proteins at the gene level. Our findings would provide effective information for subsequent exploration of the candidate genes in enhancing LD muscle development of cattle. GO term and KEGG pathway analyses contribute to further understanding the structure and function of genes. In this study, DEGs were significantly enriched in 24 GO terms and 78 pathways, of which several GO terms and pathways with high-proportioned DEGs might be associated with the WHC trait. DEGs were mainly enriched in extracellular matrix (GO:0031012), collagen-containing extracellular matrix (GO:0062023), cell adhesion (GO: 0007155), and cell surface (GO:0009986). Previous studies have reported extracellular matrix (ECM) contains many proteins such as collagens, proteoglycans, and glycoproteins that affect meat quality greatly like resulting in the improvement of WHC and regulating the tenderness of meat ${ }^{30-32}$. In addition, ECM plays roles not only in the integrity, adaptation, and growth of skeletal muscle, but also in the adaptation of myofibrillar structures and signal transduction from the extracellular matrix to the myoblast ${ }^{33}$. The cell surface is composed of lipids, proteins, and carbohydrates, which regulates cell adhesion, cell-cell interactions, and communication with the environment ${ }^{34}$. Cell adhesion is involved in constructing the right extracellular environment and the development of skeletal muscle ${ }^{35}$. Integrins that belong to the superfamily of transmembrane cell adhesion proteins can bind to ECM ligands to play an important role in cell adhesion cascades ${ }^{36}$. Studies showed that degradation of integrins had a strong correlation with WHC ${ }^{37}$. Taken together, it can be speculated that ECM, cell surface, and cell adhesion may regulate the WHC trait. KEGG pathway analysis of DEGs mainly revealed that regulation of actin cytoskeleton (bta04810), focal adhesion (bta04510), ECM-receptor interaction (bta04512), and MAPK signaling pathway (bta04010) might be the crucial candidate pathway affecting WHC. The MAPK signaling pathway is an important environmental information processing that is not only involved in cell division, transcription, and translation ${ }^{38}$, but also stimulates the growth of skeletal muscle ${ }^{39}$. The remolding of the actin cytoskeleton is a key part of cell processes. Zhao et al. indicated regulation of actin cytoskeleton was a potential candidate pathway affecting drip loss ${ }^{40}$. Huff-Lonergan et al., 
showed the changes in the architecture of myofibrils could have an impact on the ability of muscle cells to retain water, which implied the pathway of "regulation of actin cytoskeleton" involved in muscle structure perhaps was the most potential candidate pathway affecting WHC ${ }^{41}$. Focal adhesion is an integrin-containing and multi-protein assembly that is related to adhesion and cell signal transduction ${ }^{42}$. In terms of adhesion, the best-characterized aspect is muscle connection with other muscles may require an integrin-mediated linkage between the ECM and the actin cytoskeleton. All the above proves that the mentioned pathways may play special roles in the regulation of WHC.

In addition to the significantly enriched GO terms and pathways that could regulate the WHC, we revealed several candidate genes might regulate the development of WHC. Heat shock protein 70 (HSP70) was involved in WHC and tenderness due to it could protect proteins from denaturing caused by lethal heat shock ${ }^{43,44}$. In the work of Zhao et al., several HSP genes, HSPAIL, HSPB1, $H S P B 7$, and $H S P H 1$, were found to be related to drip loss ${ }^{40}$. In this study, heat shock protein family A (HSP70) member 13 (HSPA13) and heat shock protein family A (HSP70) member 12A (HSPA12A) were identified as DEGs between the H-WHC and L-WHC groups. HSPs are important elements of muscle that regulate the cytoskeleton and control cell maintenance ${ }^{45}$.The improvement of these proteins abundance could contribute to less fluid exuding from the cells, thus affecting the WHC. Peroxisome proliferator-activated receptor gamma $(P P A R \gamma)$ is a ligand-activated nuclear hormone receptor subfamily of transcription factors that expresses in adipose tissue, having many functions including regulating adipogenesis, adipocyte differentiation, and glucose homeostasis ${ }^{46}$. Previous research showed that the mutations of the CDS region in $P P A R \gamma$ had a potential correlation with WHC and tenderness ${ }^{47}$. Overall, we conclude that HSPA13, HSPA12A, and PPAR $\gamma$ play an important role in beef WHC. Myopalladin (MYPN) is an encoding genes of the sarcomere protein that regulates Z-line and I-band protein assemblies ${ }^{48}$. Studies found MYPN regulated WHC in cattle reproduction and breeding ${ }^{26}$. Interestingly, Goicoechea et al., found $M Y P N$ was an important candidate gene for meat quality selection ${ }^{49}$. Although $M Y P N$ was differentially expressed only when padj $<0.05$ in this experiment, it could also be conjectured that MYPN was a candidate gene that affected the WHC in accordance with previous studies. Triosephosphate isomerase (TPII) was differently expressed between the two groups according to two empirical criteria (padj $<0.05 \&\left|\log _{2} \mathrm{FC}\right| \geq 1$ ) in this study. TPII encodes triosephosphate isomerase that belongs to sarcoplasmic protein, which provides energy generation for muscle cells and is identified as a potential candidate gene related to beef meat quality like WHC ${ }^{50}$, drip loss ${ }^{51}$, tenderness ${ }^{52}$, meat color ${ }^{53}$, and ultimate $\mathrm{pH}^{54}$. Experiments have shown that denaturation of sarcoplasmic proteins played a special role in WHC reduction ${ }^{55}$. These results indicate that TPII may responsible for the differences in WHC. Most of the water is stored in myofibrils ${ }^{56}$, and the losses of water in meat are mainly owing to myofibrils swelling or shrinking ${ }^{57}$. Studies have indicated that denaturation of myofibrillar proteins is closely associated with low WHC ${ }^{40}$. Myosin 
is the most abundant of myofibrillar proteins that affects the development of bovine skeletal muscles ${ }^{58}$, which is composed of heavy $(M Y H)$ and light $(M Y L)$ chains ${ }^{59}$. The muscle fiber types determined by the expression of myosin heavy chain subtypes in tissues are closely related to meat quality such as WHC, drip loss, tenderness, and IMF ${ }^{60,61}$. In the present study, four myosin heavy chain family genes (MYH3, MYH8, MYH10, and MYH11) and two myosin light chain family genes (MYL2 and MYL3) were differently expressed in the H-WHC group vs L-WHC group. Among these genes, only MYH1O and MYL2 were simultaneously enriched in GO terms and pathways. MYH10, as the muscle structural protein-coding gene, plays an important role in the kinds of muscle fiber characteristics, cytoskeleton reorganization, and focal contacts formation, which influences meat quality characteristics based on positive correlation with marbling score and negative correlation with $\mathrm{pH}$ and IMF ${ }^{62,63}$. MYL family genes have been identified as potential candidate genes for WHC prediction in the research of yak muscle with different drip loss ${ }^{64}$. The above shows MYH1O and MYL2 may be potential candidate genes regulating WHC. In addition to the DEGs mentioned above that have been confirmed by previous researches, we also revealed several novel DEGs significantly enriched in more than three GO terms or pathways were likely to regulate the WHC. Integrin alpha-V (ITGAV), a member of the integrin family of extracellular matrix receptors, has been demonstrated to responsible for cell-to-matrix binding ${ }^{65}$. Integrins could attach the cytoskeleton to the extracellular matrix and affect the formation of drip channels ${ }^{66}$. Reports have shown that postmortem degradation of integrins had a positive correlation with WHC ${ }^{37}$. Fibroblast growth factor $2(F G F 2)$ is an integrin ligand that binds to integrin ITGAV:ITGB3 for FGF2 signaling, regulating skeletal myoblasts proliferation, muscle growth, cell migration, and cell survival ${ }^{67,68}$. Besides, thrombospondin-1 (THBS1) encodes the matricellular extracellular matrix adhesive glycoprotein that binds to ITGAV to regulate cellular processes such as cell-to-cell interactions, cell-to-matrix interactions, and focal adhesion disassembly ${ }^{69}$. These findings suggest ITGAV can interact with FGF2 and THBS1 to be involved in the regulation of WHC.

Collagen is an important protein in animal connective tissue that stimulates cell growth ${ }^{31}$. Several DEGs identified in this study are coding genes of the collagen family, including COL4A1, COL5A2, COL6A3, COL8A1, COL12A1, COL15A1, and COL20A1 that belong to type IV, V, VI, VIII, XII, XV, XX of collagen family, respectively. Collagen alpha-1(IV) chain (COLAAl), as the type IV collagen proteins coding gene, has also been significantly enriched in the extracellular matrix and collagen-containing extracellular matrix terms in this study. As mentioned above, ECM contains collagens, proteoglycans, and glycoproteins that contribute to the formation of WHC ${ }^{30}$. Besides, some COLAAl mutations could influence conformational domain-containing integrin-binding sites, thus led to myopathy ${ }^{70}$. Consequently, its involvement in biological processes of ECM indicates that it has an effect on the WHC.

Decorin $(D C N)$ belongs to a small leucine-rich proteoglycan (SLRP) family that is widely 
distributed in the extracellular matrix to regulate skeletal muscle mass by modulating the activity of myostatin ${ }^{71}$. It is associated with plenty of biological functions mainly as a structural and signaling molecule, which are mediated by its interactions with cytokines, extracellular matrix proteins, and cell surface receptors ${ }^{72}$. $D C N$ affected the rate of fibrils formation and decorin-induced signaling changes that led to increased cell migration ${ }^{73}$. Furthermore, studies showed that $D C N$ had considerable relevance to the formation and stabilization of collagen fibers in the perimysium, which affected muscle fibers assembled with myogenesis ${ }^{74}$. Skeletal muscles are composed of different muscle fiber types that are closely associated with WHC and drip loss ${ }^{75}$. Hence, $D C N$ may influence WHC by participating in the contractile and metabolic of skeletal muscle and the formation of muscle fibers.

Another well-known family of genes is the transforming growth factor, whose receptor family genes (TGFBR1, TGFBR2, TGFBR3, and TGFBI) were differentially expressed in the H-WHC and L-WHC groups. Among these genes, transforming growth factor-beta receptor 1 (TGFBRI) was significantly enriched in ten GO terms and nine pathways. TGFBRI belongs to the TGFB receptor subfamily that plays an important role in skeletal muscle development and TGF- $\beta$ signal transduction ${ }^{76}$. Muscle fibers are the main composition of skeletal muscle, whose development is closely associated with meat quality traits in livestock such as WHC ${ }^{61}$ and tenderness ${ }^{77}$. Additionally, many studies have shown that TGF- $\beta$ signaling is involved in cell differentiation into myofibroblasts, ECM formation, and ECM remodeling ${ }^{78}$. Therefore, biological function and pathways analyses of this gene reveal that it plays a potential role in the WHC.

\section{Conclusions}

In this study, transcriptome analysis was conducted in eight individuals with extreme WHC values. A total of 948 up-regulated and 308 down-regulated genes were identified by DESeq2 in the H-WHC group versus the L-WHC group, respectively. Additionally, we revealed several GO terms (extracellular matrix, cell adhesion, cell surface, etc.), KEGG pathways (focal adhesion, regulation of actin cytoskeleton, ECM-receptor interaction, etc.), seven genes (HSPA12A, HSPA13, PPAR , MYH10, MYL2, MYPN, and TPI1) confirmed by previous studies and six novel potential candidate genes (ITGAV, FGF2, THBS1, DCN, COLAA1, and TGFBR1) that may influence the WHC of beef cattle, among which the novel discovered candidate genes need further investigation and verification. These findings will provide basic and effective information for future relevant researches on beef quality traits, aiming to improve beef quality and flourish the beef industry.

\section{Methods}

\section{Ethics declarations}

The study was approved by the Ethics Committee of Science Research Department of the Institute of Animal Science, Chinese Academy of Agricultural Sciences (CAAS), Beijing, China (approval 
number: RNL 09/07). All the animal procedures were not only performed strictly according to the guidelines proposed by the China Council on Animal Care and the Ministry of Agriculture People's Republic of China, but also in compliance with the Animal Research: Reporting In Vivo Experiments (ARRIVE) guidelines. The use of anilmals and private land in this study was approved by their respective legal owners.

\section{Animals and sample collection}

A total of 49 Chinese Simmental beef bulls with an average age of 26 months and an average pre-slaughter weight of $700 \mathrm{~kg}$ were obtained to eliminate the influence of farm, age, and sex differences on the results of the longissimus dorsi (LD) muscle transcriptome. These cattle were from Inner Mongolia Aokesi Livestock Breeding Co., Ltd and were raised in the same feeding strategies and conditions. Slaughtering and sampling were completed in Zhongao Food Co., Ltd (Aohan Banner, Chifeng City, Inner Mongolia). Cattle stopped feeding and drinking strictly 24 hours before slaughter. The longissimus dorsi (LD) muscle (12-13th ribs) was harvested within 30 min after slaughter and the samples were washed with phosphate-buffered saline (PBS) to avoid contaminating the muscle tissues during the operation. Afterward, pieces of LD muscle tissues were obtained and put into Eppendorf (EP) tubes. All samples were immediately frozen in liquid nitrogen for total RNA extraction. In addition, $1 \mathrm{~kg}$ of the LD muscle (11-13th ribs) of the left carcass per sample was collected at $24 \mathrm{~h}$ after slaughter to measure meat traits including WHC and the rate of $35 \mathrm{~kg}$ water loss using TA-XT plus Texture Analyser 12785 (Stable Micro Systems Ltd, Godalming, Surrey GU7 1YL, UK) according to reference NY/T 1333-2007.

Total RNA extraction, library construction, and sequencing

Total RNA was isolated from individual LD tissue using TRIzol reagent (Invitrogen, Life Technologies) according to the protocol of instruction. The concentration, purity, and integrity of RNA were used to evaluate the total RNA quality. The RNA concentration was tested by Qubit ${ }^{\circledR}$ RNA Assay Kit(Life Technologies, CA, USA), RNA purity was assessed using NanoPhotometer® spectrophotometer(Thermo Fisher Scientific, MA, USA), and RNA integrity was measured through the RNA Nano 6000 Assay Kit of the Bioanalyzer 2100 system (Agilent Technologies, CA, USA). Then, high-quality samples (28S/18S > 1.8 and OD 260/280 ratio > 1.9) were used to construct cDNA libraries and applied for RNA sequencing if the RNA Integrity Number (RIN) was more than 7. The construction of cDNA libraries was generated using IlluminaTruSeqTM RNA Kit(Illumina, USA) following the manufacturer's instructions and the RNA sequencing was performed on an Illumina NovaSeq 6000 platform by paired-end strategy (read length $150 \mathrm{bp}$ ). The RNA sequencing was completed by Beijing Novogene Technology Co., Ltd.

\section{Quality control of sequencing data}

To obtain clean reads, the MD5 value was used to check the integrity of the original sequencing 
read. Using FastQC (v0.11.9) to evaluate the read quality in terms of base composition and quality distribution, then visualizing all sequencing results through MultiQC(v1.9). Using adaptive trimming algorithm of Trimmomatic (v0.39) tools to perform quality filtering, discarding reads containing ploy-N (the percentage of undetermined base information is greater than 5\% in a read), trimming adaptors and low-quality reads. Subsequent data analysis is based on clean reads obtained through the above steps.

\section{Reads mapping}

HISAT2 (v2.2.1) was used to compare clean reads to reference genome Bos taurus ARS-UCD1.2 (ftp://ftp.ensembl.org/pub/release-101/fasta/bos_taurus/dna/) ${ }^{79}$. Effective reads aligned to the gene region were statistically calculated according to the genomic location information specified by the cattle reference genome annotation (ftp://ftp.ensembl.org/pub/release-101/gtf/bos_taurus/). SAM files generated by the HISAT2 were sorted through SAMtools (v1.11). FeatureCounts (v1.5.2) was used to estimate read counts generated from RNA sequencing experiments ${ }^{80}$.

\section{Differentially expressed genes identification and function enrichment analysis}

All the cattle were sorted in descending order of the WHC value and eight individuals with significant differences in the WHC were selected for analyzing their transcriptome differences to identify potential candidate genes affecting the WHC. Differential gene expression analysis was analyzed using DESeq2 (v1.18.0) ${ }^{81}$, which provides statistical routines for calculating differential expression based on the negative binomial distribution. Benjamini-Hochberg approach was used to adjust P-values for controlling the false discovery rate (FDR). Genes with padj $<0.05$ and $\log _{2} \mathrm{FC} \geq 1$ or $\log _{2} \mathrm{FC} \leq-1$ were identified as DEGs. Heatmap was drawn by pheatmap (v1.1.7) package ${ }^{82}$. To understand the function of DEGs, GO and KEGG pathway enrichment analyses were performed using the R package "clusterProfiler" based on the hypergeometric model ${ }^{83}$. GO term analysis was divided into three categories, namely, biological process (BP), cellular component (CC), and molecular function(MF). KEGG pathway analysis revealed the role of DEGs in metabolic pathways and specific biological functions. Those GO terms and pathways showing an adjusted p-value of less than 0.01 and q-value less than 0.05 for each term were considered to be significantly enriched. We further used the Search Tool for the Retrieval of Interacting Genes (STRING) to carry out protein-protein interaction (PPI) network analysis.

\section{DEGs comparison with the QTLs and previous reports affecting WHC}

With the development of high-throughput sequencing technologies, the genetic mapping of quantitative trait loci (QTL) has provided well-defined genetic maps for meat quality traits ${ }^{84}$. The Animal Quantitative Trait Loci (QTL) Database (Animal QTLdb) is open and free of charge that provides dynamic, updated publicly available trait mapping data to locate and compare discoveries within and between species. Up to now, a total of 160,659 QTLs/associations from 1,030 
438 publications that contain 675 phenotypic traits have been collected in the current release of the 439 Cattle QTL database (QTLdb, https://www.animalgenome.org/cgi-bin/QTLdb/BT/index). In order 440 to screen the DEGs for the candidate genes associated with beef WHC, we compared the DEGs 441 with QTLs in the cattle QTLdb and previous reports of WHC trait. The DEGs mapping to QTL 442 related to the WHC trait deserved further investigation and discussion.

\section{Statistical analysis of animal performance}

444 Using the Independent-Sample T-test procedure of SPSS (v20.0) to assess the measurement results 445 of meat traits. All data presented in the table were expressed as means \pm standard deviation $(\mathrm{M} \pm$ SD). Meat quality evaluation by reference NY/T 1333-2007.

447 
4811 Li, Y. et al. Transcriptome profiling of longissimus lumborum in Holstein bulls and ste ers with different beef qualities. PLoS One 15, e0235218, doi:10.1371/journal.pone.023 5218 (2020). Barbera, S. WHCtrend, an up-to-date method to measure water holding capacity in $\mathrm{m}$ eat. Meat science 152, 134-140, doi:10.1016/j.meatsci.2019.02.022 (2019). a targeting fibro-adipogenic progenitor cells in meat animals. Animal : an internationa I journal of animal bioscience 14, 312-321, doi:10.1017/s175173111900209x (2020). ljaz, M. et al. Association between meat color of DFD beef and other quality attribut es. Meat science 161, 107954, doi:10.1016/j.meatsci.2019.107954 (2020). Bhuiyan, M. S. A. et al. Genetic parameters of carcass and meat quality traits in diff erent muscles (longissimus dorsi and semimembranosus) of Hanwoo (Korean cattle). J ournal of animal science 95, 3359-3369, doi:10.2527/jas.2017.1493 (2017). Gonzalez-Rivas, P. A. et al. Effects of heat stress on animal physiology, metabolism, a nd meat quality: A review. Meat science 162, 108025, doi:10.1016/j.meatsci.2019.1080 25 (2020). ducts: a review of recent research advances. Critical reviews in food science and nutr ition 48, 137-159, doi:10.1080/10408390601177647 (2008).

Honikel, K. O. Reference methods for the assessment of physical characteristics of me at. Meat science 49, 447-457, doi:10.1016/s0309-1740(98)00034-5 (1998). Martínez, A., Aldai, N., Celaya, R. \& Osoro, K. Effect of breed body size and the mus cular hypertrophy gene in the production and carcass traits of concentrate-finished ye arling bulls. Journal of animal science 88, 1229-1239, doi:10.2527/jas.2009-2025 (201 $0)$.

ytterhaegen, L. et al. Effects of double-muscling on carcass quality, beef tenderness and myofibrillar protein degradation in Belgian Blue White bulls. Meat science 38, 25 5-267, doi:10.1016/0309-1740(94)90115-5 (1994). texture traits of meat from yearling bulls. Meat science 68, 567-575, doi:10.1016/j.m eatsci.2004.05.008 (2004).

Abou-Kassem, D. E., El-Kholy, M. S., Alagawany, M., Laudadio, V. \& Tufarelli, V. Age a nd sex-related differences in performance, carcass traits, hemato-biochemical paramete rs, and meat quality in Japanese quails. Poultry science 98, 1684-1691, doi:10.3382/ps /pey543 (2019). $\mathrm{m}$ Beef Cattle Subjected to Non-penetrative and Penetrative Percussive Stunning Meth ods. Asian-Australasian journal of animal sciences 26, 723-731, doi:10.5713/ajas.2012.1 2563 (2013).

14 Kim, Y. H. B., Meyers, B., Kim, H. W., Liceaga, A. M. \& Lemenager, R. P. Effects of st epwise dry/wet-aging and freezing on meat quality of beef loins. Meat science 123, 57-63, doi:10.1016/j.meatsci.2016.09.002 (2017).

15 Jung, E. Y., Hwang, Y. H. \& Joo, S. T. The Relationship between Chemical Composition 
S, Meat Quality, and Palatability of the 10 Primal Cuts from Hanwoo Steer. Korean jo urnal for food science of animal resources 36, 145-151, doi:10.5851/kosfa.2016.36.2.14 5 (2016).

16 Wen, Y. et al. Analysis of the physical meat quality in partridge (Alectoris chukar) an d its relationship with intramuscular fat. Poultry science 99, 1225-1231, doi:10.1016/j. psj.2019.09.009 (2020).

17 Jennen, D. G. et al. Genetic aspects concerning drip loss and water-holding capacity of porcine meat. J Anim Breed Genet 124 Suppl 1, 2-11, doi:10.1111/j.1439-0388.200 7.00681.x (2007).

18 Bendall, J. R. \& Swatland, H. J. A review of the relationships of $\mathrm{pH}$ with physical asp ects of pork quality. Meat science 24, 85-126, doi:10.1016/0309-1740(88)90052-6 (198 8).

19 Farouk, M. M., Mustafa, N. M., Wu, G. \& Krsinic, G. The "sponge effect" hypothesis: an alternative explanation of the improvement in the waterholding capacity of meat with ageing. Meat science 90, 670-677, doi:10.1016/j.meatsci.2011.10.012 (2012).

20 Hwang, J. H. et al. Associations of the Polymorphisms in DHRS4, SERPING1, and APO $\mathrm{R}$ Genes with Postmortem pH in Berkshire Pigs. Animal biotechnology 28, 288-293, d oi:10.1080/10495398.2017.1279171 (2017).

$21 \mathrm{Xu}, \mathrm{X}$. et al. Porcine CSRP3: polymorphism and association analyses with meat quality traits and comparative analyses with CSRP1 and CSRP2. Mol Biol Rep 37, 451-459, d oi:10.1007/s11033-009-9632-1 (2010).

22 Zappaterra, M., Sami, D. \& Davoli, R. Association between the splice mutation g.8283 C>A of the PHKG1 gene and meat quality traits in Large White pigs. Meat science 1 48, 38-40, doi:10.1016/j.meatsci.2018.10.003 (2019).

23 Qiao, M. et al. Imprinting analysis of porcine DIO3 gene in two fetal stages and asso ciation analysis with carcass and meat quality traits. Mol Biol Rep 39, 2329-2335, doi: 10.1007/s11033-011-0983-z (2012).

$24 \mathrm{Wu}, \mathrm{W}$. et al. Identification of four SNPs and association analysis with meat quality $\mathrm{t}$ raits in the porcine Pitx2c gene. Sci China Life Sci 54, 426-433, doi:10.1007/s11427-01 1-4167-9 (2011).

25 Fan, Y. Y., Fu, G. W., Fu, C. Z., Zan, L. S. \& Tian, W. Q. A missense mutant of the P PAR $-\gamma$ gene associated with carcass and meat quality traits in Chinese cattle breeds. Genetics and molecular research : GMR 11, 3781-3788, doi:10.4238/2012.August.17.4 (2012).

26 Jiao, Y., Zan, L. S., Liu, Y. F., Wang, H. B. \& Guo, B. L. A novel polymorphism of the MYPN gene and its association with meat quality traits in Bos taurus. Genetics and molecular research : GMR 9, 1751-1758, doi:10.4238/vol9-3gmr906 (2010).

27 Reardon, W., Mullen, A. M., Sweeney, T. \& Hamill, R. M. Association of polymorphis $\mathrm{ms}$ in candidate genes with colour, water-holding capacity, and composition traits in bovine $M$. longissimus and $M$. semimembranosus. Meat science 86, 270-275, doi:10.1 016/j.meatsci.2010.04.013 (2010).

Sun, X. et al. Effects of polymorphisms in CAPN1 and CAST genes on meat tendernes $s$ of Chinese Simmental cattle. Archives animal breeding 61, 433-439, doi:10.5194/aab61-433-2018 (2018). 
Stark, R., Grzelak, M. \& Hadfield, J. RNA sequencing: the teenage years. Nature revie ws. Genetics 20, 631-656, doi:10.1038/s41576-019-0150-2 (2019).

30 Nishimura, T. Role of extracellular matrix in development of skeletal muscle and post mortem aging of meat. Meat science 109, 48-55, doi:10.1016/j.meatsci.2015.05.015 (2 015).

31 Sorushanova, A. et al. The Collagen Suprafamily: From Biosynthesis to Advanced Biom aterial Development. Adv Mater 31, e1801651, doi:10.1002/adma.201801651 (2019). Theocharis, A. D., Skandalis, S. S., Gialeli, C. \& Karamanos, N. K. Extracellular matrix structure. Advanced drug delivery reviews 97, 4-27, doi:10.1016/j.addr.2015.11.001 (20 16).

33 Kjaer, M. Role of extracellular matrix in adaptation of tendon and skeletal muscle to mechanical loading. Physiological reviews 84, 649-698, doi:10.1152/physrev.00031.2003 (2004).

34 Kuhlmann, L., Cummins, E., Samudio, I. \& Kislinger, T. Cell-surface proteomics for the identification of novel therapeutic targets in cancer. Expert review of proteomics 15, 2 59-275, doi:10.1080/14789450.2018.1429924 (2018).

35 Maartens, A. P. \& Brown, N. H. The many faces of cell adhesion during Drosophila muscle development. Developmental biology 401, 62-74, doi:10.1016/j.ydbio.2014.12.03 8 (2015).

36 Kling, D., Fingerle, J. \& Harlan, J. M. Inhibition of leukocyte extravasation with a mon oclonal antibody to CD18 during formation of experimental intimal thickening in rabbi $\mathrm{t}$ carotid arteries. Arteriosclerosis and thrombosis : a journal of vascular biology 12, 9 97-1007, doi:10.1161/01.atv.12.9.997 (1992).

37 Straadt, I. K., Rasmussen, M., Young, J. F. \& Bertram, H. C. Any link between integrin degradation and water-holding capacity in pork? Meat science 80, 722-727, doi:10.10 16/j.meatsci.2008.03.012 (2008).

38 Wagner, E. F. \& Nebreda, A. R. Signal integration by JNK and p38 MAPK pathways in cancer development. Nature reviews. Cancer 9, 537-549, doi:10.1038/nrc2694 (2009).

Ito, N., Ruegg, U. T. \& Takeda, S. ATP-Induced Increase in Intracellular Calcium Levels and Subsequent Activation of mTOR as Regulators of Skeletal Muscle Hypertrophy. In ternational journal of molecular sciences 19, doi:10.3390/ijms19092804 (2018).

40 Zhao, X. et al. Comparative gene expression profiling of muscle reveals potential cand idate genes affecting drip loss in pork. BMC Genet 20, 89, doi:10.1186/s12863-019-07 94-0 (2019).

41 Huff-Lonergan, E. \& Lonergan, S. M. New frontiers in understanding drip loss in pork: recent insights on the role of postmortem muscle biochemistry. J Anim Breed Genet 124 Suppl 1, 19-26, doi:10.1111/j.1439-0388.2007.00683.x (2007).

42 Duperret, E. K. \& Ridky, T. W. Focal adhesion complex proteins in epidermis and squ amous cell carcinoma. Cell cycle (Georgetown, Tex.) 12, 3272-3285, doi:10.4161/cc.263 85 (2013).

43 Grosz, M. D., Skow, L. C. \& Stone, R. T. An Alul polymorphism at the bovine 70 kD heat-shock protein-1 (HSP70-1) locus. Anim Genet 25, 196, doi:10.1111/j.1365-2052.19 94.tb00113.x (1994). 
Genomics 45, 1012-1020, doi:10.1152/physiolgenomics.00066.2013 (2013). nctions. Cell stress \& chaperones 22, 601-611, doi:10.1007/s12192-017-0787-8 (2017). European journal of pharmacology 785, 44-49, doi:10.1016/j.ejphar.2015.11.004 (201 6).

Fan, Y. Y. et al. Three novel SNPs in the coding region of PPARY gene and their asso ciations with meat quality traits in cattle. Mol Biol Rep 38, 131-137, doi:10.1007/s110 33-010-0086-2 (2011).

48 Bang, M. L. et al. Myopalladin, a novel 145-kilodalton sarcomeric protein with multipl e roles in Z-disc and I-band protein assemblies. The Journal of cell biology 153, 413427, doi:10.1083/jcb.153.2.413 (2001).

49 Goicoechea, S. M., Arneman, D. \& Otey, C. A. The role of palladin in actin organizati on and cell motility. European journal of cell biology 87, 517-525, doi:10.1016/j.ejcb.2 008.01.010 (2008).

50 Huff Lonergan, E., Zhang, W. \& Lonergan, S. M. Biochemistry of postmortem muscle lessons on mechanisms of meat tenderization. Meat science 86, 184-195, doi:10.101 6/j.meatsci.2010.05.004 (2010).

51 Di Luca, A., Elia, G., Hamill, R. \& Mullen, A. M. 2D DIGE proteomic analysis of early post mortem muscle exudate highlights the importance of the stress response for $\mathrm{i}$ mproved water-holding capacity of fresh pork meat. Proteomics 13, 1528-1544, doi:10. 1002/pmic.201200145 (2013).

52 Picard, B. et al. Beef tenderness and intramuscular fat proteomic biomarkers: muscle type effect. PeerJ 6, e4891, doi:10.7717/peerj.4891 (2018).

53 Gagaoua, M., Monteils, V., Couvreur, S. \& Picard, B. Identification of Biomarkers Assoc iated with the Rearing Practices, Carcass Characteristics, and Beef Quality: An Integrat ive Approach. Journal of agricultural and food chemistry 65, 8264-8278, doi:10.1021/a cs.jafc.7b03239 (2017).

54 Gagaoua, M., Couvreur, S., Le Bec, G., Aminot, G. \& Picard, B. Associations among Pr otein Biomarkers and $\mathrm{pH}$ and Color Traits in Longissimus thoracis and Rectus abdomi nis Muscles in Protected Designation of Origin Maine-Anjou Cull Cows. Journal of agri cultural and food chemistry 65, 3569-3580, doi:10.1021/acs.jafc.7b00434 (2017). Marcos, B. \& Mullen, A. M. High pressure induced changes in beef muscle proteome: correlation with quality parameters. Meat science 97, 11-20, doi:10.1016/j.meatsci.20 13.12.008 (2014).

56 Wei, W. et al. Identification of key microRNAs affecting drip loss in porcine longissim us dorsi by RNA-Seq. Gene 647, 276-282, doi:10.1016/j.gene.2018.01.005 (2018).

Offer, G. \& Trinick, J. On the mechanism of water holding in meat: The swelling and shrinking of myofibrils. Meat science 8, 245-281, doi:10.1016/0309-1740(83)90013-x (1983).

Kim, G. D., Yang, H. S. \& Jeong, J. Y. Comparison of Characteristics of Myosin Heavy Chain-based Fiber and Meat Quality among Four Bovine Skeletal Muscles. Korean jour nal for food science of animal resources 36, 819-828, doi:10.5851/kosfa.2016.36.6.819 (2016). 


\begin{tabular}{|c|c|c|}
\hline 56 & 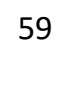 & $\begin{array}{l}\text { Djima, K. Myosin: Formation and maintenance of thick filaments. Animal science journ } \\
\text { al = Nihon chikusan Gakkaiho 90, 801-807, doi:10.1111/asj.13226 (2019). }\end{array}$ \\
\hline & 0 & $\begin{array}{l}\text { hang, M. et al. Expression of MyHC genes, composition of muscle fiber type and th } \\
\text { eir association with intramuscular fat, tenderness in skeletal muscle of Simmental hyb } \\
\text { ids. Mol Biol Rep 41, 833-840, doi:10.1007/s11033-013-2923-6 (2014). }\end{array}$ \\
\hline & 1 & $\begin{array}{l}\text { Kim, G. D., Ryu, Y. C., Jeong, J. Y., Yang, H. S. \& Joo, S. T. Relationship between por } \\
\text { k quality and characteristics of muscle fibers classified by the distribution of myosin } \\
\text { heavy chain isoforms. Journal of animal science 91, 5525-5534, doi:10.2527/jas.2013-6 } \\
614 \text { (2013). }\end{array}$ \\
\hline & 62 & $\begin{array}{l}\text { Ovilo, C. et al. Longissimus dorsi transcriptome analysis of purebred and crossbred lb } \\
\text { erian pigs differing in muscle characteristics. BMC Genomics 15, 413, doi:10.1186/147 } \\
1-2164-15-413 \text { (2014). }\end{array}$ \\
\hline & 63 & $\begin{array}{l}\text { Wu, F. et al. Effect of skeletal muscle fibers on porcine meat quality at different stag } \\
\text { es of growth. Genetics and molecular research : GMR 14, 7873-7882, doi:10.4238/201 } \\
\text { 5.July.14.13 (2015). }\end{array}$ \\
\hline & 64 & $\begin{array}{l}\text { Zuo, H. et al. Proteome changes on water-holding capacity of yak longissimus lumbor } \\
\text { um during postmortem aging. Meat science 121, 409-419, doi:10.1016/j.meatsci.2016.0 } \\
7.010 \text { (2016). }\end{array}$ \\
\hline & 65 & $\begin{array}{l}\text { Loeser, H. et al. Integrin alpha V (ITGAV) expression in esophageal adenocarcinoma is } \\
\text { associated with shortened overall-survival. Sci Rep 10, 18411, doi:10.1038/s41598-020 } \\
-75085-7 \text { (2020). }\end{array}$ \\
\hline & 66 & $\begin{array}{l}\text { Lawson, M. A. The role of integrin degradation in post-mortem drip loss in pork. Me } \\
\text { at science 68, 559-566, doi:10.1016/j.meatsci.2004.05.019 (2004). }\end{array}$ \\
\hline & 7 & $\begin{array}{l}\text { Woad, K. J. et al. Fibroblast growth factor } 2 \text { is a key determinant of vascular sprouti } \\
\text { ng during bovine luteal angiogenesis. Reproduction (Cambridge, England) 143, 35-43, } \\
\text { doi:10.1530/rep-11-0277 (2012). }\end{array}$ \\
\hline & 68 & $\begin{array}{l}\text { Ghanim, H. et al. Effect of Testosterone on FGF2, MRF4, and Myostatin in Hypogona } \\
\text { dotropic Hypogonadism: Relevance to Muscle Growth. The Journal of clinical endocrin } \\
\text { ology and metabolism 104, 2094-2102, doi:10.1210/jc.2018-01832 (2019). }\end{array}$ \\
\hline & 69 & $\begin{array}{l}\text { Murphy-Ullrich, J. E. Thrombospondin } 1 \text { and Its Diverse Roles as a Regulator of Extra } \\
\text { cellular Matrix in Fibrotic Disease. The journal of histochemistry and cytochemistry : o } \\
\text { fficial journal of the Histochemistry Society 67, 683-699, doi:10.1369/002215541985110 } \\
3 \text { (2019). }\end{array}$ \\
\hline & 70 & $\begin{array}{l}\text { Cavallin, M. et al. Further refinement of COL4A1 and COL4A2 related cortical malfor } \\
\text { mations. European journal of medical genetics 61, 765-772, doi:10.1016/j.ejmg.2018.10. } \\
004 \text { (2018). }\end{array}$ \\
\hline & 71 & $\begin{array}{l}\text { Velleman, S. G. The role of the extracellular matrix in skeletal muscle development. } P \\
\text { oultry science 78, 778-784, doi:10.1093/ps/78.5.778 (1999). }\end{array}$ \\
\hline & 72 & $\begin{array}{l}\text { Franczyk, M., Wawrzykowski, J. \& Kankofer, M. Preliminary results of the placental de } \\
\text { corin profile in bovine pregnancy and parturition. Glycoconjugate journal 35, 461-465, } \\
\text { doi:10.1007/s10719-018-9834-7 (2018). }\end{array}$ \\
\hline & 73 & $\begin{array}{l}\text { Tufvesson, E. \& Westergren-Thorsson, G. Biglycan and decorin induce morphological a } \\
\text { nd cytoskeletal changes involving signalling by the small GTPases RhoA and Rac1 resu } \\
\text { Iting in lung fibroblast migration. Journal of cell science 116, 4857-4864, doi:10.1242/j }\end{array}$ \\
\hline
\end{tabular}


74 Nishimura, T., Futami, E., Taneichi, A., Mori, T. \& Hattori, A. Decorin expression durin $\mathrm{g}$ development of bovine skeletal muscle and its role in morphogenesis of the intram uscular connective tissue. Cells, tissues, organs 171, 199-214, doi:10.1159/000063713 (2002).

75 Koomkrong, N. et al. Fiber characteristics of pork muscle exhibiting different levels of drip loss. Animal science journal = Nihon chikusan Gakkaiho 88, 2044-2049, doi:10.1 111/asj.12859 (2017).

76 Loeys, B. L. et al. A syndrome of altered cardiovascular, craniofacial, neurocognitive a nd skeletal development caused by mutations in TGFBR1 or TGFBR2. Nature genetics 37, 275-281, doi:10.1038/ng1511 (2005).

77 Hwang, Y. H., Kim, G. D., Jeong, J. Y., Hur, S. J. \& Joo, S. T. The relationship betwee $\mathrm{n}$ muscle fiber characteristics and meat quality traits of highly marbled Hanwoo (Kore an native cattle) steers. Meat science 86, 456-461, doi:10.1016/j.meatsci.2010.05.034 (2010).

78 Verstraeten, A., Alaerts, M., Van Laer, L. \& Loeys, B. Marfan Syndrome and Related D isorders: 25 Years of Gene Discovery. Human mutation 37, 524-531, doi:10.1002/humu. 22977 (2016).

79 Kim, D., Langmead, B. \& Salzberg, S. L. HISAT: a fast spliced aligner with low memor y requirements. Nature methods 12, 357-360, doi:10.1038/nmeth.3317 (2015).

80 Liao, Y., Smyth, G. K. \& Shi, W. featureCounts: an efficient general purpose program $f$ or assigning sequence reads to genomic features. Bioinformatics (Oxford, England) 30, 923-930, doi:10.1093/bioinformatics/btt656 (2014).

81 Varet, H., Brillet-Guéguen, L., Coppée, J. Y. \& Dillies, M. A. SARTools: A DESeq2- and EdgeR-Based R Pipeline for Comprehensive Differential Analysis of RNA-Seq Data. PLoS One 11, e0157022, doi:10.1371/journal.pone.0157022 (2016).

$82 \mathrm{Ni}, \mathrm{W}$. et al. Identification of cancer-related gene network in hepatocellular carcinoma by combined bioinformatic approach and experimental validation. Pathology, research and practice 215, 152428, doi:10.1016/j.prp.2019.04.020 (2019).

83 Yu, G., Wang, L. G., Han, Y. \& He, Q. Y. clusterProfiler: an R package for comparing biological themes among gene clusters. Omics : a journal of integrative biology 16, 2 84-287, doi:10.1089/omi.2011.0118 (2012).

84 Leal-Gutiérrez, J. D., Elzo, M. A., Johnson, D. D., Hamblen, H. \& Mateescu, R. G. Gen ome wide association and gene enrichment analysis reveal membrane anchoring and structural proteins associated with meat quality in beef. BMC Genomics 20, 151, doi: 10.1186/s12864-019-5518-3 (2019).

$85 \mathrm{Li}, \mathrm{R}$. et al. Exploring the IncRNAs Related to Skeletal Muscle Fiber Types and Meat Quality Traits in Pigs. Genes (Basel) 11, doi:10.3390/genes11080883 (2020). 


\section{Acknowledgements}

The author thanks Tianpeng Chang, Bingxing An, Mang Liang, Xinghai Duan, and all members of the labs for their suggestions and comments on this experiment. This work was supported by National Natural Science Foundation of China (31872975), Chinese Academy of Agricultural Sciences of Technology Innovation Project (CAAS-XTCX2016010, CAAS-ZDXT2018006, and ASTIP-IAS03), Program of National Beef Cattle and Yak Industrial Technology System (CARS-37). The funders played no role in study design, in the collection, analysis, in the writing of the manuscript, and in the decision to submit the manuscript for publication.

\section{Author contributions statement}

H.J.G. and J.Y.L. designed and supervised the experiments. L.L.D. and T.P.C. performed the experiments and drafted the manuscript. B.X.A., M.L., and X.H.D. analyzed the data. W.T.C., B.Z., X.G., Y.C., and L.P.Z. helped to conduct the study. All authors have read and approved the final manuscript.

\section{Availability materials}

The following are available at supplementary materials, Supplementary Table S1 Phenotypic information of WHC and other traits for the low and high samples, Supplementary Table S2 The primary information of sequencing reads alignments to Bos taurus reference genome, Supplementary Table S3 All DEGs detected between high and low WHC groups, Supplementary Table S4 GO terms significantly enriched with DEGs , Tsupplementary able S5 Top 20 pathways enriched based on the number of DEGs enriched per pathway, Supplementary Table S6 All KEGG pathways significantly enriched with DEGs , Supplementary Table S7 The detailed information candidate genes affecting WHC trait, Supplementary Table S8 The information of potential candidate genes involved in GO terms and pathways, Supplementary Table S9 Comparison of DEGs with QTLdb and previous reports influencing WHC or drip loss.

\section{Consent for publication}

Not applicable.

\section{Competing interests}

The authors declare that they have no competing interests. 
Figure 1. Samples correlation analysis and identification of DEGs between high WHC and low WHC groups. (A) PCA of the identified genes. The red and green dots represent samples of high WHC and low WHC, respectively. The high WHC and low WHC samples were obviously clustered. (B) Volcano plot for DEGs in LD muscle comparing high WHC group versus low WHC group. The red and green dots represent significant up-regulated (FC $\geq 2$ and padj $\leq 0.05)$ and down-regulated (FC $\leq 0.5$ and padj $\leq 0.05)$ DEGs, respectively. Dots of other colors indicate genes that are not significant. The purple dots denote genes with $\mathrm{FC} \geq 2$ or FC $\leq 0.5$ and padj $>0.05$, while the blue dots indicate genes only meet the condition of padj $\leq 0.05$. The black dots represent genes with no significant change $(0.5<\mathrm{FC}<2$ and padj $>0.05)$. (C) Heatmap of DEGs. Columns and rows show samples and DEGs, respectively. Red indicates high level gene expression in H-WHC versus L-WHC group, while blue represents low level gene expression in H-WHC versus L-WHC group.

Figure 2. GO terms and KEGG pathways analyses of all DEGs between H-WHC and L-WHC groups. The $\mathrm{x}$-axis and $\mathrm{y}$-axis represent the number of DEGs enriched per GO term or KEGG pathway, and the most highly enriched GO terms or pathways, respectively. Three GO categories (BP, CC, and MF) and four KEGG A_Class are shown in different colors. The numbers in the figure represent the number of DEGs enriched to each GO term or pathway.

Figure 3. The network diagram of the most critical DEGs and their belonged GO terms and pathways. Blue, purple, and orange squares represent the enriched GO terms. Green squares represent the enriched pathways. Gene marked in blue displays the critical DEGs that may be candidate genes affecting the WHC.

Figure 4. PPI network of the critical candidate genes affecting the WHC. Genes marked in red represent they have been confirmed by predecessors to be related to WHC, while the potential candidate genes influencing WHC found in this experiment are marked in blue. 


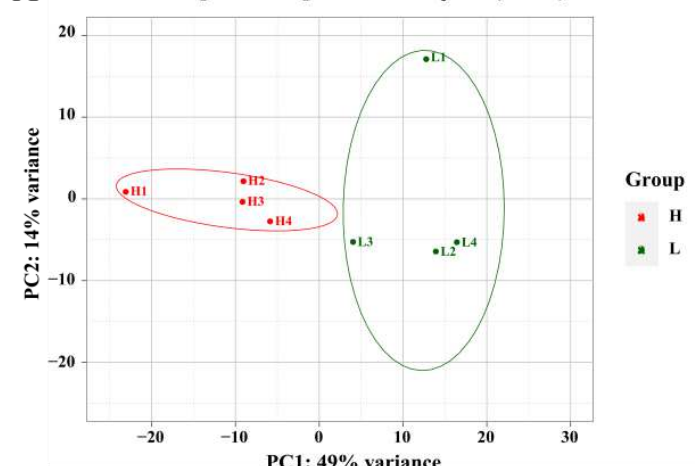

B

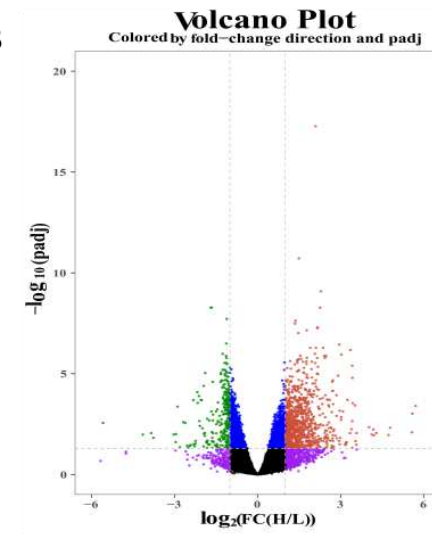

C
Diff_gene_heatmap

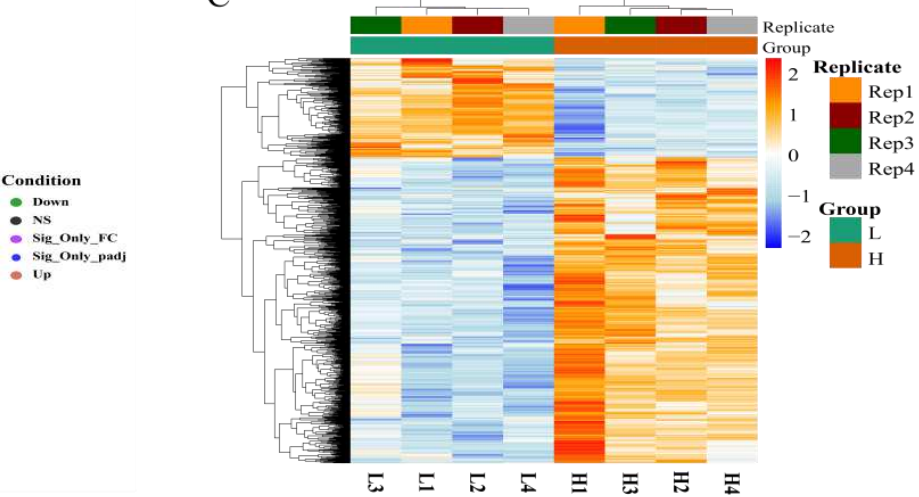

A

B
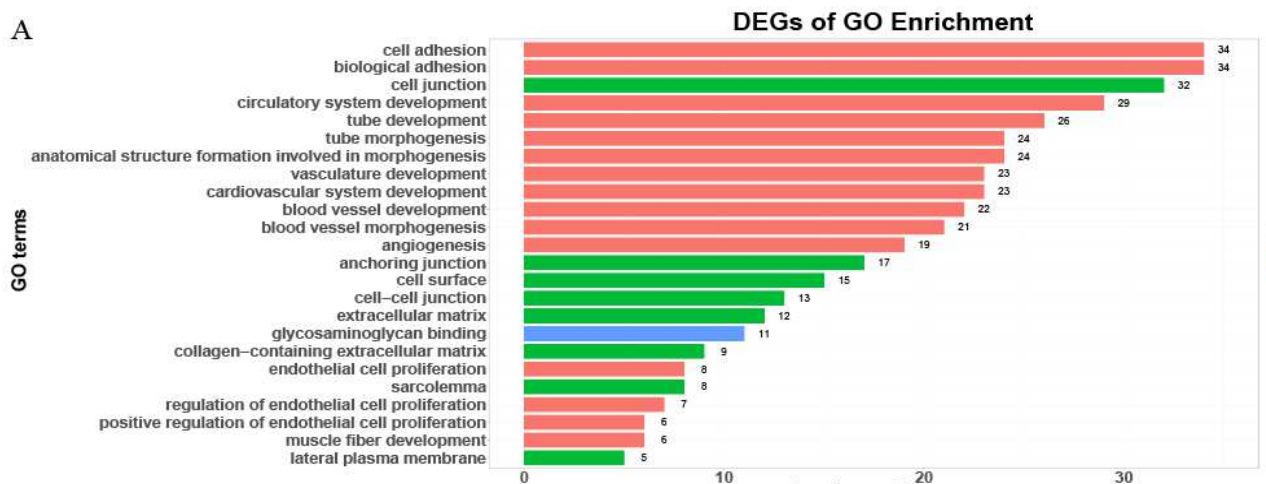

ONTOLOGY

$\mathrm{BP}$
$\mathrm{CC}$
$\mathrm{MF}$

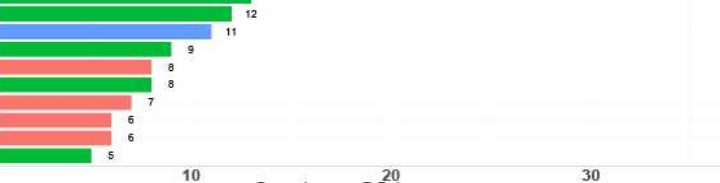

10 Counts per Go term

DEGs of KEGG pathway analysis

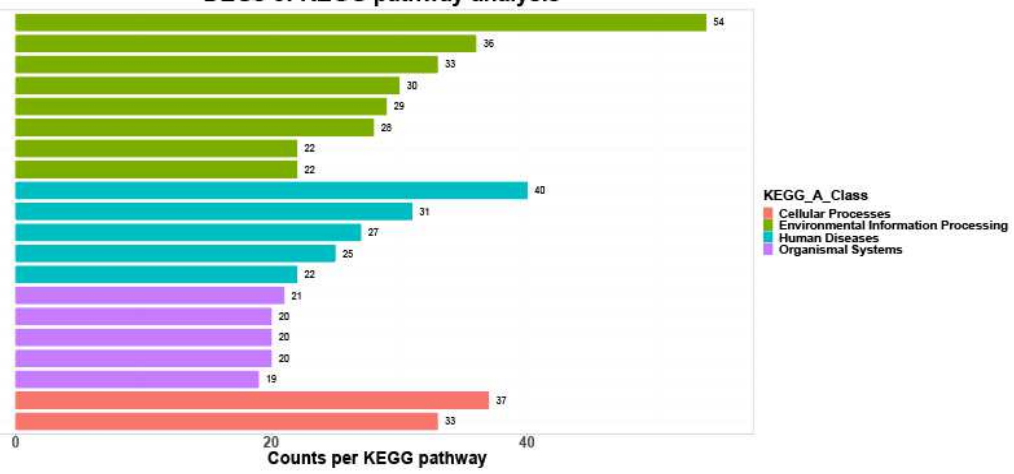




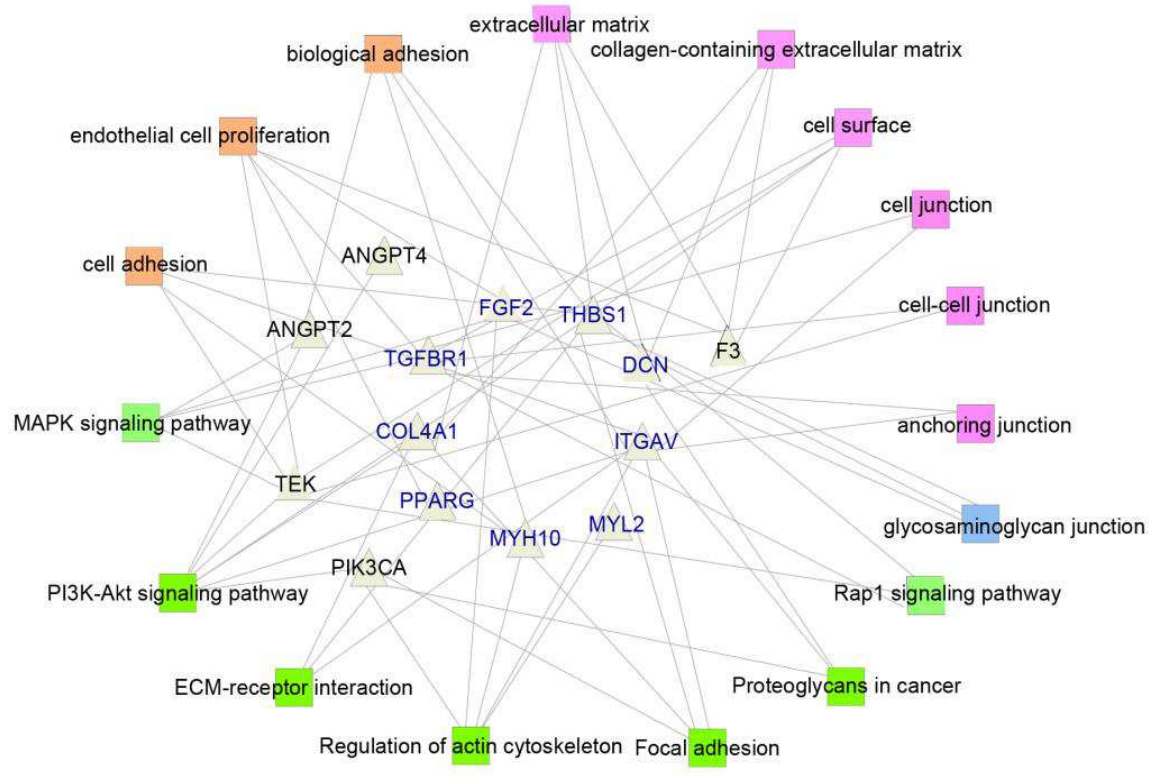

807

808

809

810

4

811

812

813

814

815

816

817

818 
821 Table 1. Summary of statistical data for WHC and other traits between samples with high WHC (n $822=4)$ and low WHC $(\mathrm{n}=4)$, respectively.

\begin{tabular}{lllll}
\hline Characters & All samples measured & High WHC group & Low WHC group & p \\
\hline WHC $(\%)$ & $0.50 \pm 0.08$ & $0.62 \pm 0.09$ & $0.39 \pm 0.07$ & 0.009 \\
$\begin{array}{l}35 \mathrm{~kg} \text { Water loss }(\%) \\
\text { Weight for }\end{array}$ & $0.36 \pm 0.06$ & $0.28 \pm 0.07$ & $0.45 \pm 0.05$ & 0.007 \\
pre-slaughter $(\mathrm{kg})$ & $702.5 \pm 78.49$ & $751.0 \pm 69.06$ & $668.3 \pm 92.69$ & 0.206 \\
\hline
\end{tabular}

$\mathrm{p}=\mathrm{p}$-value calculated by Independent-Sample T-test procedure of SPSS (v20.0)

824 The results are shown by mean \pm standard deviation

Table 2. Summary of sequencing reads alignments to the Bos taurus reference genome

\begin{tabular}{lllll}
\hline Sample & Clean reads & Total mapped reads $(\%)$ & $\begin{array}{l}\text { Uniquely mapped } \\
\text { reads }(\%)\end{array}$ & $\begin{array}{l}\text { Multiple mapped } \\
\text { reads }(\%)\end{array}$ \\
\hline H1 & $21,688,061$ & 97.32 & 92.13 & 2.71 \\
H2 & $23,789,046$ & 97.23 & 91.52 & 3.21 \\
H3 & $19,721,321$ & 96.98 & 91.07 & 3.31 \\
H4 & $21,220,022$ & 96.86 & 90.98 & 3.18 \\
L1 & $29,214,147$ & 96.93 & 90.98 & 3.75 \\
L2 & $26,307,213$ & 96.87 & 90.48 & 3.71 \\
L3 & $20,406,566$ & 96.86 & 90.75 & 3.58 \\
L4 & $24,622,189$ & 97.16 & 91.79 & 3.28 \\
\hline
\end{tabular}
represent four samples of the lowest WHC groups. 
Table 3. Most important GO terms and pathways of DEGs between H-WHC and L-WHC groups

\begin{tabular}{|c|c|c|c|c|}
\hline Classification & GO term/pathway & p-value & $\begin{array}{l}\text { Number } \\
\text { of genes }\end{array}$ & Key genes \\
\hline \multirow[t]{8}{*}{ GO terms } & cell adhesion & $1.41 \mathrm{E}-07$ & $34(3)$ & ITGAV/THBSI/MYHIO \\
\hline & biological adhesion & $2.14 \mathrm{E}-07$ & $34(3)$ & ITGAV/THBSI/MYHIO \\
\hline & $\begin{array}{l}\text { endothelial cell } \\
\text { proliferation }\end{array}$ & 2.77E-04 & $8(3)$ & $T G F B R 1 / F G F 2 / P P A R \gamma$ \\
\hline & cell junction & $1.20 \mathrm{E}-03$ & $32(2)$ & ITGAV/TGFBRI \\
\hline & anchoring junction & $1.06 \mathrm{E}-04$ & $17(2)$ & ITGAV/TGFBRI \\
\hline & cell surface & 1.49E-04 & $15(2)$ & TGFBRI/THBS1 \\
\hline & extracellular matrix & $4.12 \mathrm{E}-05$ & $12(3)$ & DCN/THBSI/COLAAI \\
\hline & $\begin{array}{l}\text { collagen-containing } \\
\text { extracellular matrix }\end{array}$ & $7.06 \mathrm{E}-05$ & $9(2)$ & $D C N / C O L 4 A 1$ \\
\hline \multirow[t]{5}{*}{ Pathways } & $\begin{array}{l}\text { MAPK signaling } \\
\text { pathway }\end{array}$ & $9.66 \mathrm{E}-07$ & $36(5)$ & $\begin{array}{l}\text { TEK/TGFBR1/TGFBR2/FGF2/ } \\
\text { FGFR1 }\end{array}$ \\
\hline & Focal adhesion & $8.76 \mathrm{E}-12$ & $37(3)$ & ITGAV/ITGA6/COL6A3 \\
\hline & $\begin{array}{l}\text { Regulation of actin } \\
\text { cytoskeleton }\end{array}$ & $1.92 \mathrm{E}-08$ & $33(2)$ & ITGAV/ITGA6 \\
\hline & $\begin{array}{l}\text { ECM-receptor } \\
\text { interaction }\end{array}$ & $2.45 \mathrm{E}-06$ & $17(7)$ & $\begin{array}{l}\text { ITGAV/IITGA6/ITGA8/ITGA9/ } \\
\text { COL4A1/COL6A3/THBSI }\end{array}$ \\
\hline & $\begin{array}{l}\text { Cell adhesion } \\
\text { molecules }\end{array}$ & $4.53 \mathrm{E}-03$ & $17(4)$ & ITGAV/ITGA6/ITGA8/ ITGA9 \\
\hline
\end{tabular}

848

849

850

851

852

853

854

855

856

857

858

859

860

861

GO: Gene Ontology

KEGG: Kyoto Encyclopedia of Genes and Genomes

DEGs: differently expressed genes

MAPK: mitogen-activated protein kinase

ECM: extracellular matrix

Number of genes: the first number represent the total number of genes enriched in per GO term or pathway; the second number represents the number of key genes displayed in the next column. 
Table 4. Six potential candidate genes affecting the WHC between two groups

\begin{tabular}{lcllll}
\hline Symbol & BTA & $\log _{2}$ FC & padj & Gene position (bp) & Gene description \\
\hline ITGAV & 2 & 1.47 & $5.83 \mathrm{E}-05$ & $9644368-9749556$ & integrin subunit alpha V \\
$F G F 2$ & 17 & 1.60 & $5.31 \mathrm{E}-04$ & $34801330-34860849$ & fibroblast growth factor 2 \\
THBS 1 & 10 & 2.28 & $8.21 \mathrm{E}-10$ & $35209595-35224867$ & thrombospondin 1 \\
DCN & 5 & 1.22 & $2.77 \mathrm{E}-03$ & $21014376-21053400$ & decorin \\
COL4A1 & 12 & 1.12 & $2.13 \mathrm{E}-02$ & $84863917-84995777$ & collagen type IV alpha 1 chain \\
& & & & & transforming growth factor beta \\
TGFBRI & 8 & 1.23 & $3.12 \mathrm{E}-03$ & $64107418-64179245$ & receptor 1 \\
\hline
\end{tabular}

864

WHC: water holding capacity

865 BTA: Bos taurus Autosome

866 FC: fold change

867 padj: p-value adjusted by false discovery rate (FDR)

868 Gene position (bp): position (bp) on ARS-UCD1.2

869

870 Table 5. Previous reports related to WHC or drip loss

\begin{tabular}{lllll}
\hline Symbol & BTA & Gene position(bp) & GC content(\%) & Reference \\
\hline HSPA1L & 23 & $27523225-27527209$ & 45.55 & Reference $^{40}$ \\
HSPB1 & 25 & $34345339-34347009$ & 67.44 & Reference $^{40}$ \\
HSPB7 & 2 & $136053155-136057934$ & 64.67 & Reference $^{40}$ \\
HSPH1 & 12 & $29796159-29819628$ & 39.42 & Reference $^{40}$ \\
PPAR & 22 & $56709248-56835386$ & 41.26 & Reference $^{25,47}$ \\
MYH1 & 19 & $29483027-29507056$ & 41.84 & Reference $^{61}$ \\
MYH7 & 10 & $21325414-21345624$ & 55.05 & Reference $^{85}$ \\
MYH10 & 19 & $28063029-28183409$ & 44.00 & Reference $^{61}$ \\
MYL2 & 17 & $54706765-54714580$ & 44.93 & Reference $^{64}$ \\
MYPN & 28 & $24679611-24593260$ & 39.69 & Reference $^{26}$ \\
MSTN & 2 & $3631373-3851228$ & 34.05 & Reference $^{9}$ \\
TPI1 & 5 & $103580087-103583951$ & 60.26 & Reference $^{50}$ \\
\hline
\end{tabular}

871 BTA: Bos taurus Autosome

872 Gene position (bp): position (bp) on ARS-UCD1.2 
Figures

\section{A Principal Component Anhysis (PCA)}

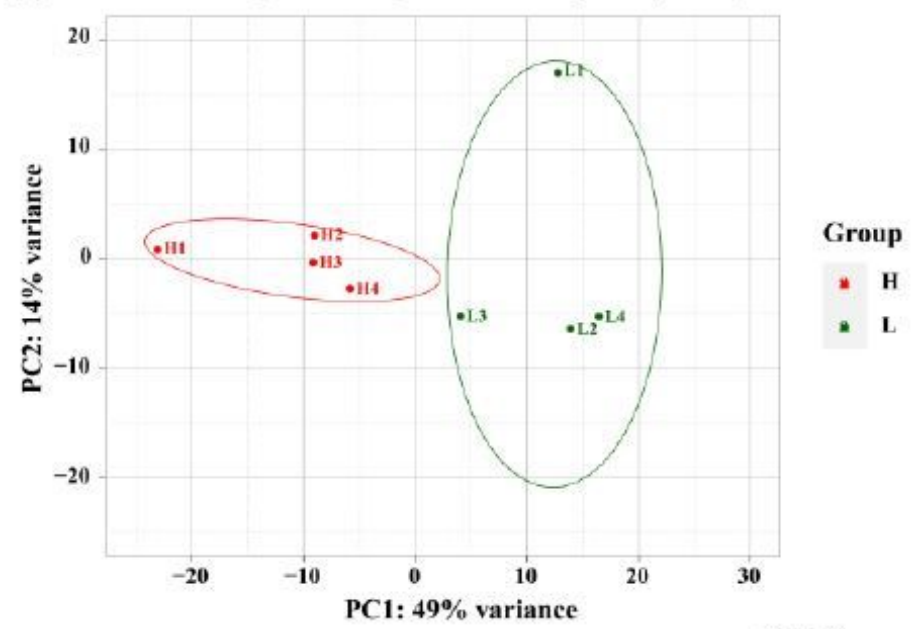

B

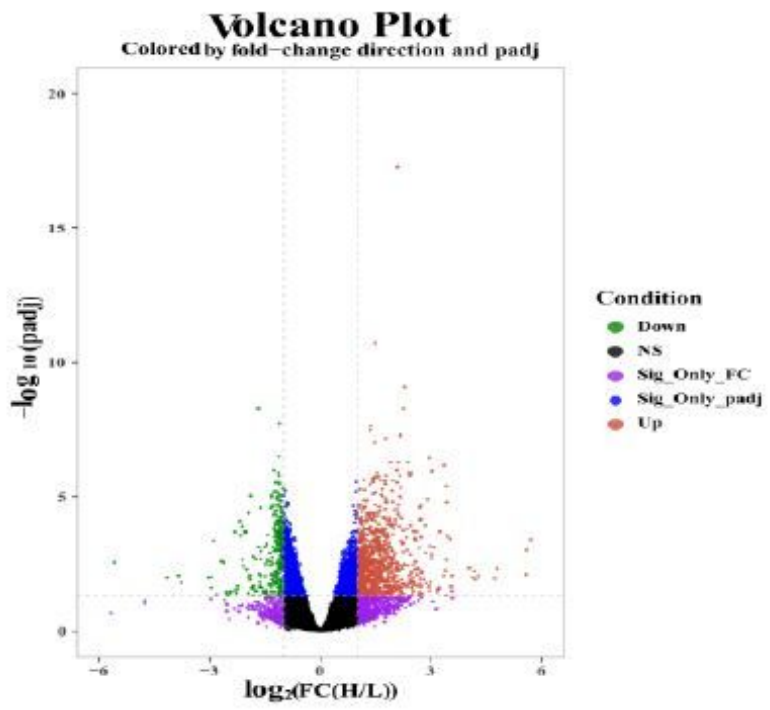

$\mathrm{C}$
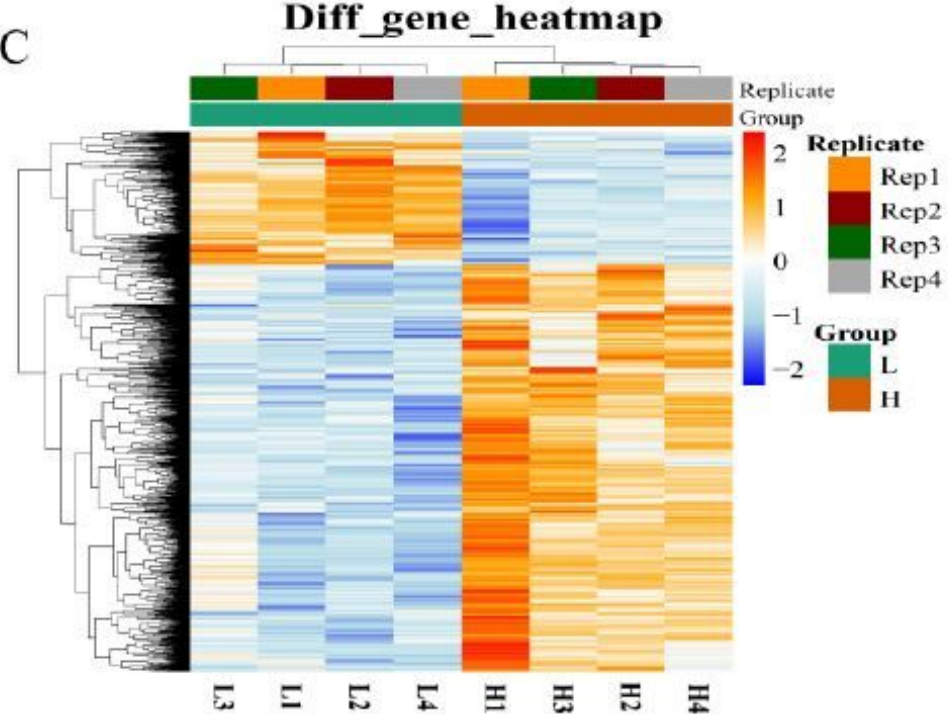

Figure 1

"See the Supplemental Files section for the complete figure caption". 
A

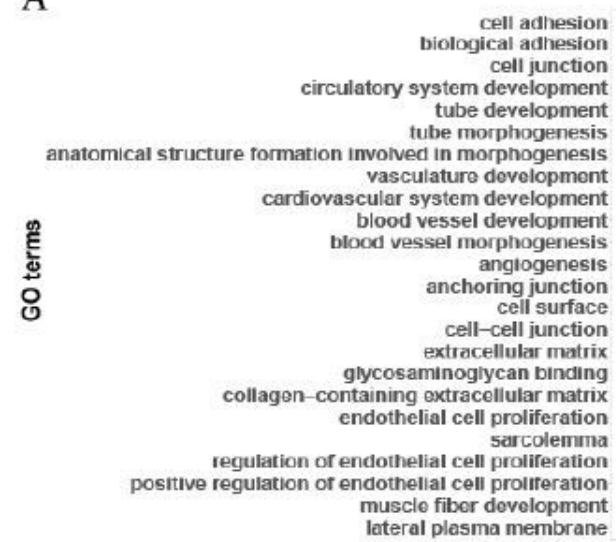

B

PI3K-Akt signaling pathway MAPK signaling pathway Ras signaling pathway Rap1 signaling pathway Calclum signaling pathway CGMP-PKG signaling pathway Apelin signaling pathway Phospholipase $D$ signaling pathway Human papillomavirus infection Proteoglycans in cancer

Human cytomegalovirus infection MicroRNAs in cancer Kaposi sarcoma-associated herpesvirus infection Estrogen signaling pathway Vascular smooth muscle contraction Adrenergic signaling in cardiomyocytes Cholinergic synapse
Focal adhesion Regulation of actin cytoskeleton
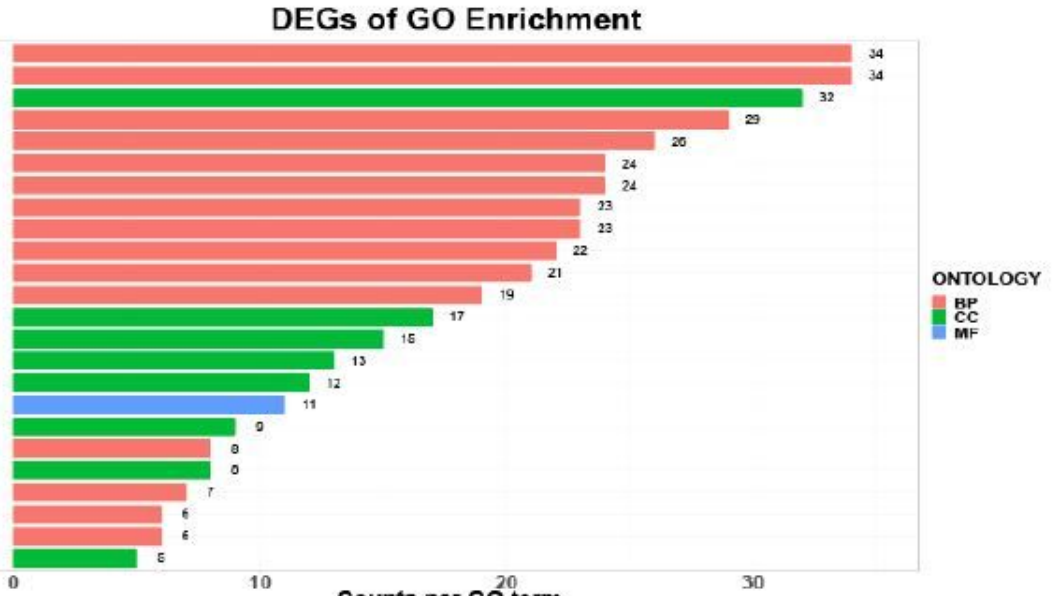

DEGs of KEGG pathway analysis

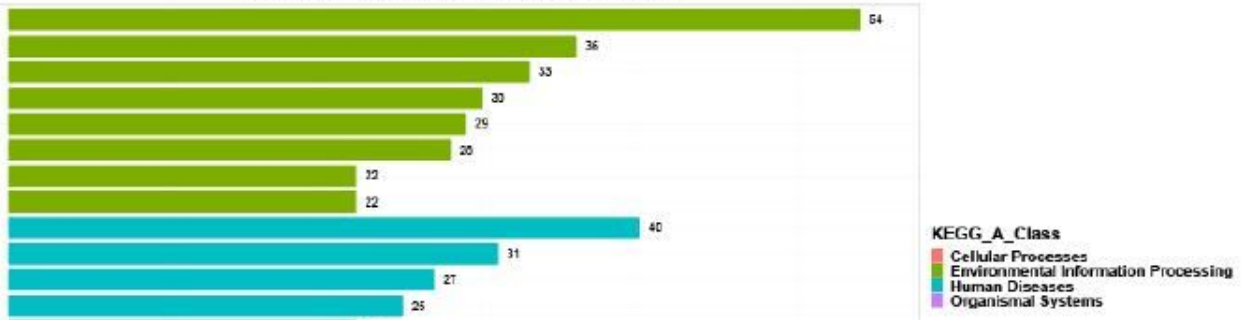

Figure 2

"See the Supplemental Files section for the complete figure caption". 


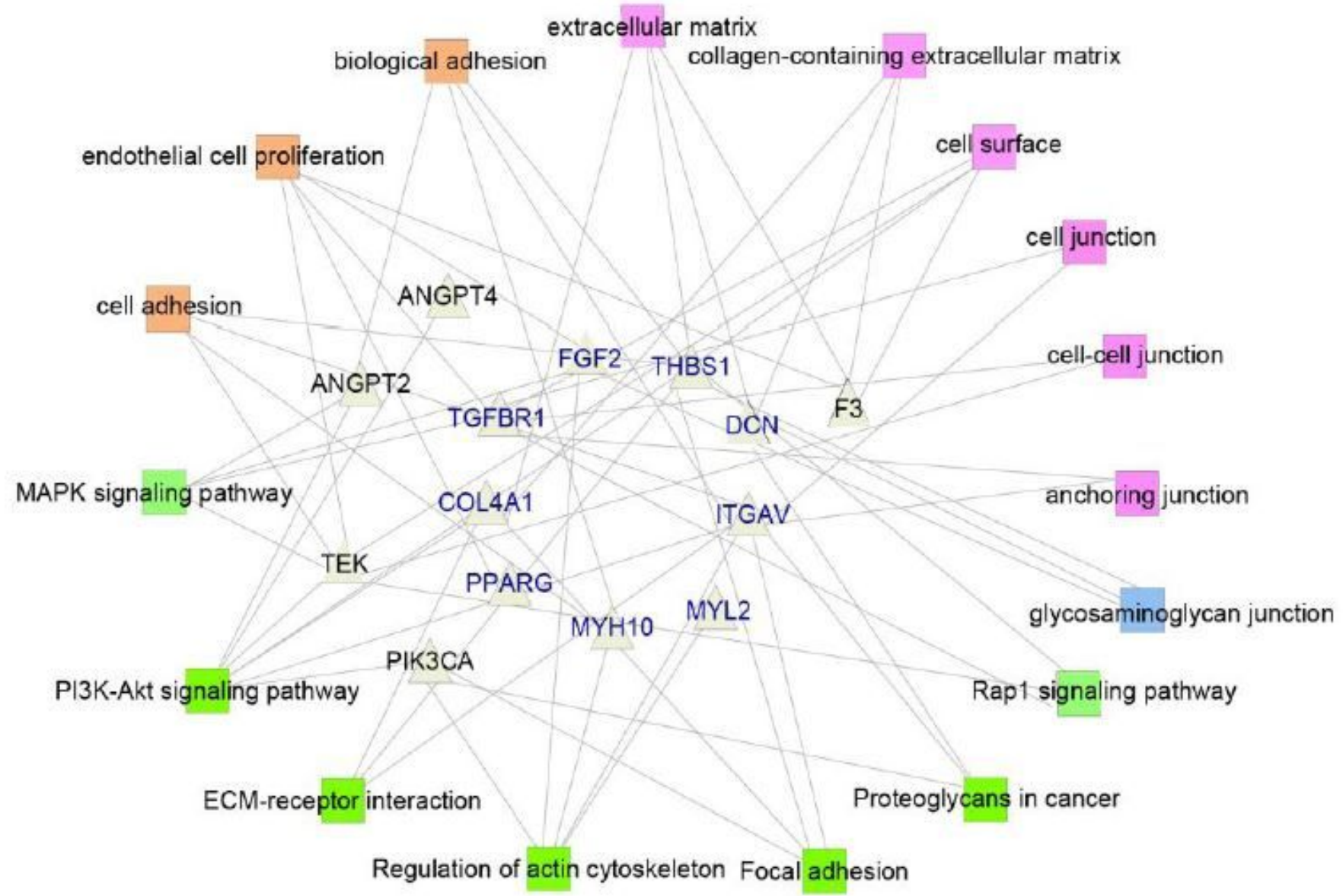

\section{Figure 3}

"See the Supplemental Files section for the complete figure caption". 


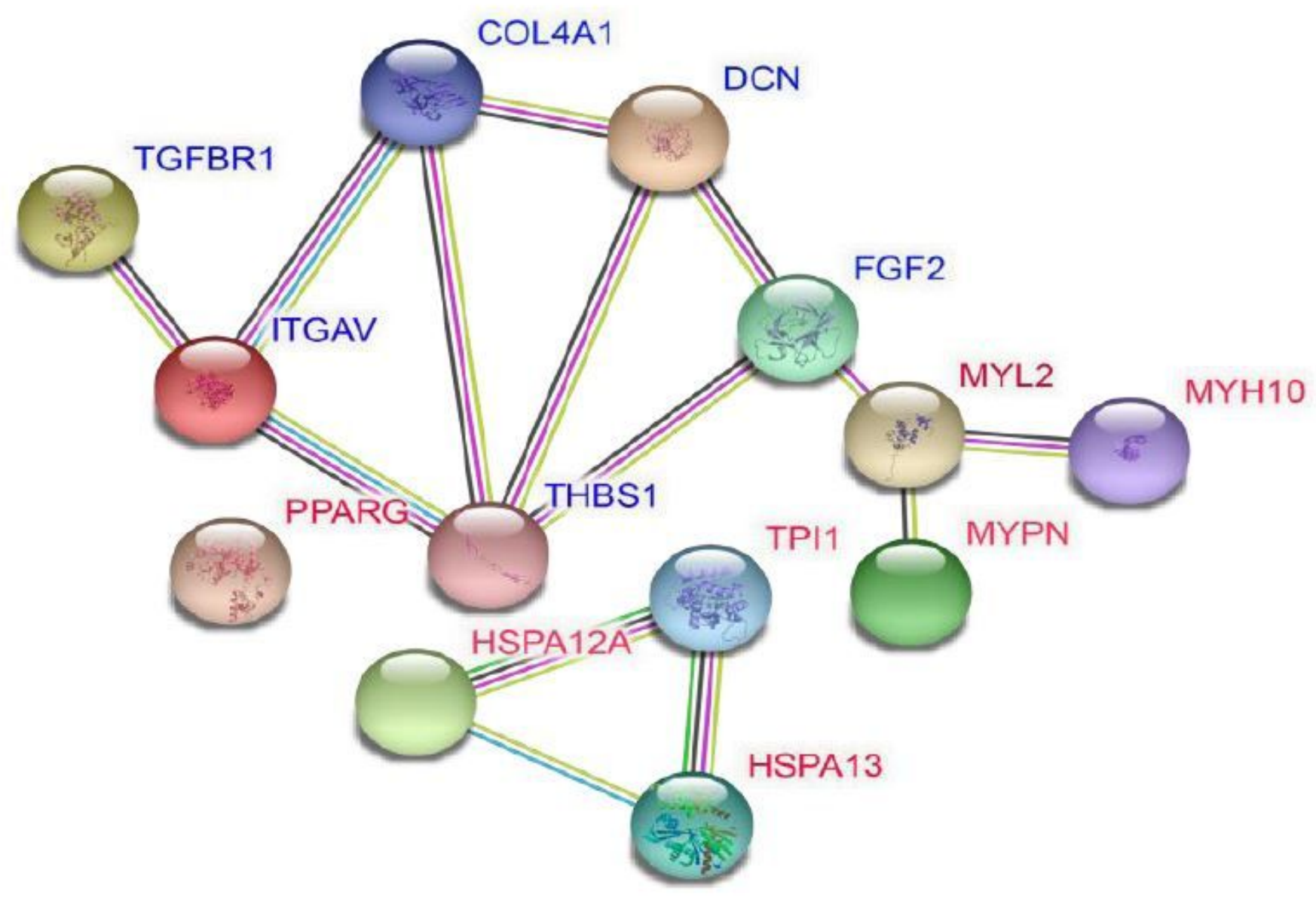

Figure 4

"See the Supplemental Files section for the complete figure caption".

\section{Supplementary Files}

This is a list of supplementary files associated with this preprint. Click to download.

- TableS1PhenotypicinformationofWHCandothertraitsforthelowandhighsamples.xIsx

- TableS2Theprimaryinformation of sequencingreadsalignmentstoBostaurusreferencegenome.xlsx

- TableS3AlIDEGsdetectedbetweenhighandlowWHCgroups.xlsx

- TableS4GOtermssignificantlyenrichedwithDEGs.xlsx

- TableS5Top20pathwaysenrichedbasedonthenumberofDEGsenrichedinperpathway.xIsx

- TableS6AllKEGGpathwayssignificantlyenrichedwithDEGs.xIsx

- TableS7ComparisonofDEGswithQTLsinfluencingWHC.xlsx

- TableS8ThedetailedinformationcandidategenesaffectingWHCtrait.xIsx 
- FigureCaptions.pdf

- TableS9TheinformationofcandidategenesinvolvedinsomesignificantGOtermsandKEGGpathways.xIsx 